\title{
La ética: Polémica en el curriculum escolar
}

\author{
Isabel Carrillo, Silvia López y Montserrat Payá
}

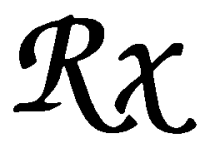

Se analiza a continuación la polémica generada en torno a la educación moral y cívica a lo largo de las últimas décadas $y$, en especial, la derivada de la LOGSE al dotar a la Etica de un carácter transversal generando nuevos planteamientos y perspectivas que procuran su mayor sistematización en el curriculum escolar.

La propuesta de reforma del sistema educativo inició un debate en torno a la disyuntiva entre la ética como asignatura específica o como reflexión y trabajo interdisciplinar. La primera alternativa pareció encontrar su mayor dificultad en determinar quién había de encargarse de esta área, poniendo al descubierto la necesidad de una formación específica para el profesorado que tuviera que impartir esta materia, junto a la especificación de cuáles habían de ser sus contenidos. Sin embargo no creemos que el tratamiento transversal de la ética, que como tal nos parece adecuado, pueda por sí solo solucionar los problemas planteados. Es evidente que a nivel de contenidos algunas áreas ofrecen temas que permiten vincular la reflexión moral, pero ¿quién, dentro ya de los apretados currículums escolares, va a dedicar parte de su tiempo a la reflexión ética cuando, en ocasiones, no se dispone de recursos y materiales que orienten esta práctica? ¿Acaso para ésta, aunque su tratamiento sea interdisciplinar, no hace falta una formación específica que proporcione al profesorado los recursos que les permitan favorecer el desarrollo racional y autónomo del juicio moral de sus alúmnos/as?

Es necesario llamar la atención a quienes se plantean y dan alternativas a estos - y otros - interrogantes, de la conveniencia de mirar hacia atrás en la Historia, a principios de nuestro siglo, cuando teóricos de la educación, pedagogos y profesorado de a pie justificaban el interés y la necesidad de una educación moral y cívica en el seno de las escuelas laicas. Al igual que en las tres primera décadas del siglo XX, las discusiones sobre este tema vuelven a resurgir, quizás para superar el peligro de las posturas relativistas - que niegan la existencia de valores consensuados, reduciendo el proceso de valoración a la mera decisión individualista-, y el de los modelos de educación moral basados en 
valores absolutos, donde la persona debe adaptarse a aquellos principios que le vienen impuestos desde fuera. Se ha puesto de manifiesto que ni una ni otra postura pueden obtener resultados satisfactorios en una sociedad democrática y pluralista que defiende el desarrollo autónomo de la persona atendiendo y respetando los principios presentes en nuestra Constitución (justicia, libertad, igualdad, pluralismo político), así como el valor de la Declaración Universal de los Derechos Humanos.

En los inicios de este siglo que ya finaliza, la preocupación por la educación moral y cívica está patente en las nuevas propuestas educativas de Europa y América. La existencia de una gran parte de la población que edificaba su vida moral al margen de toda confesión religiosa justificaba este interés por una nueva moral cívica - no antirreligiosa-, que no podía someterse al control de ninguna confesión, aunque tampoco olvidaba el respeto a la educación familiar, ya fuera confesional o laica. Los aspectos y los temas relevantes fueron apuntándose desde diferentes organismos, en la celebración de congresos ${ }^{1}$, conferencias, escuelas de verano ${ }^{2}$, etc. Algunas de las reflexiones realizadas permiten, por lo menos, justificar que la práctica escolar de nuestros días no debe olvidar la necesidad de una educación moral con un mayor grado de sistematización del que permite su referencia aprovechando las diversas materias escolares. Si no fuera así, ¿cómo conseguir los objetivos que ha de contemplar la educación ético-moral en la escuela para atender a la formación integral de los alumnos? Durante la celebración de los diferentes congresos, conferencias, etc., se señalaba que el principio que debía guiar la educación nueva era la libertad. La educación moral debía impartirse sin dogmatismos, teniendo en cuenta el interés personal del alumnado y potenciando el autogobierno y la educación en sí, es decir, se hacía hincapié en el respeto a la personalidad libre y creadora del educando, defendiendo su autonomía. La primera condición de la educación debía ser la moral personal. Se trataba, en definitiva, como proponía Piaget (19717, de ayudar al alumno/a en un proceso que iba desde la heteronomía a la autonomía moral.

Junto a esto, la escuela debía ofrecer un ambiente social y humano rico en sugestiones éticas, libre de prejuicios y basado en principios de equidad. Desde la práctica escolar se debía aprovechar todas las circunstancias favorables para invitar a la reflexión moral, pero sin olvidar la enseñanza mediante «lecciones directas» que habían de ser vivenciadas como reales por el alumnado. Estas «lecciones morales» (Piaget, 1967) en ningún caso debían concebirse como clases magistrales bajo un diálogo unidireccional. Como todas las materias escolares, la educación moral debía ser redescubierta por cada alumno/a en concreto, mediante una búsqueda verdadera y una actividad espontánea. Eran necesarias la colaboración y la iniciativa por parte de los educandos, que debían sentirse miembros activos y responsables de la colectividad escolar, en un ambiente de afecto y respeto mutuo. Por otra parte, la educación moral y cívica no había de ignorar la problemática social, responsabilizando a los alumnos/as para que colaboraran en la vida de la comunidad, despertando en ellos los sentimientos y los valores de justicia, solidaridad, generosidad, cooperación, etc. Había que suscitar en el alumnado una sana curiosidad, e interesarlo por los acontecimientos de la vida contemporánea para combatir la indiferencia y el escepticismo. Desde este planteamiento, el papel del profesorado se basaba principalmente en percibir las motivaciones de los educandos para orientar positivamente sus emociones y conductas, pero no mediante procedimientos basados en la coacción y en la imposición de normas. 
Debían ofrecer a sus alumnos/as el mayor número posible de ocasiones para que pudieran educarse mutua y espontáneamente entre sí, es decir, haciéndose responsables de su propia formación.

Junto a estos principios que debían guiar la educación moral, se planteó un debate en torno a dos cuestiones. La primera era la relación existente entre educación moral y educación religiosa, criticándose a los que insistían en que no era necesaria una educación moral, puesto que ésta ya existía en la escuela por medio de la educación religiosa. Señalaban que esta forma de pensar intentaba ignorar los problemas y vacíos existentes en la enseñanza. El objetivo era impartir en la escuela pública una enseñanza moral capaz de suplir eficazmente la religión, pero sin olvidar que la libertad de conciencia suponía el respeto a la conciencia confesional de cada uno. La educación moral debía tener presentes los principios de neutralidad y de tolerancia recíproca. Se trataba de una moral constructiva basada en el respeto a la conciencia y la libertad de pensamiento. En segundo lugar, se reflexionaba sobre el interrogante que aquí nos ocupa. Se puso de manifiesto que en algunas escuelas se dedicaba explícitamente atención a la educación moral, planteándose si se habían de dedicar clases especiales o si, por el contrario, tenía que ser de carácter incidental. El principal argumento a favor de la sistematización era que la educación incidental fácilmente degenera en educación accidental y, cuando esto sucede, los resultados no son satisfactorios. El planteamiento incidental únicamente conseguiría el efecto deseado cuando el profesorado reconociera explícitamente como objetivo la edu- . cación moral y cívica de los educandos/as, prestando atención para aprovechar las diversas situaciones que permiten su aprendizaje. Esto planteaba también la necesidad de formar especialistas en educadción moral, al igual que en otros campos de conocimiento.

Situándonos ya en el momento actual, la L.O.G.S.E. opta por dotar a la ética de un carácter transversal, con el subsiguiente peligro de limitarse a una mera educación accidental. Estas consideraciones han hecho surgir nuevos planteamientos y perspectivas que intentan dotar a la educación ética de una mayor sistematización dentro del currículum escolar. Una de estas alternativas, ampliamente difundida y aplicada en territorio M.E.C. y en diferentes Comunidades Autónomas, es la que recoge el Proyecto CIVES (1989), que se plantea la necesidad de reservar en el currículum un espacio para la reflexión ético-política. El ciclo educativo que consideran idóneo para desarrollar este tipo de actividad es la futura Secundaria Obligatoria (Primer y Segundo Nivel), dadas las características evolutivas de los alumnos/as. Su propuesta de bloques temáticos intenta compaginar tanto contenidos de reflexión ético-cívica como cuestiones de carácter socio-moral, mediante un enfoque teórico y constructivista de los conceptos planteados, lo que parece potenciar la reflexión ético-cívica antes que la propiamente moral. Otra alternativa, en proceso experimental y puesta en práctica en diferentes centros educativos de Barcelona y provincia (Cornellá del Llobregat) desde el curso académico 1989-90, es la que plantea G.R.E.M. (Grupo de Investigación Moral. Universidad de Barcelona) del que formamos parte. El punto de partida es un modelo de educación moral fundamentado en la construcción autónoma y racional de valores, actitudes y normas. Este objetivo se pretende desarrollar durante toda la futura Enseñanza Obligatoria (6-16 años), partiendo de aquellos contenidos moralmente significativos para los alumnos/as de cada ciclo educativo y/o moralmente relevantes, y atendiendo a los diferentes ámbitos de relación: personal, iguales, familiar, escolar y social. 
De lo anteriormente planteado se deduce que no es suficiente con dotar a la acción pedagógica en el ámbito de la educación ético-moral de un carácter de transversalidad, ya que este tratamiento interdisciplinar puede únicamente favorecer, en el mejor de los casos, la reflexión acerca de ciertos temas sociomorales surgidos de los contenidos propios de la diversas áreas de conocimiento, pero, en cambio, no posibilita en modo alguno la reflexión en profundidad de ciertos temas que suponen un conflicto de valores y que no pueden plantearse a propósito de los contenidos curriculares específicos. Nos estamos refiriendo a aquellos temas conflictivos que emanan de los diferentes ámbitos de relación intra e inter-personal. Cuestiones tales como el autoconocimiento, la vida escolar, la relación familiar, etc., necesitan plantearse directamente en el aula, ya sea como demanda del grupo-clase o como iniciativa del profesorado. Aún en el supuesto de que éste se plantee como objetivo la educación ético-moral de sus alumnos/as, y aproveche las áreas de conocimiento que porporcionan situaciones favorables para la discusión de estos temas de carácter macro-ético, entendemos que los currículums específicos son ya suficientemente complejos y condensados para trabajar dichos temas con la profundidad y seriedad que se merecen. Atendiendo a esta limitación, y junto a la imposibilidad de tratar otros contenidos que no surgen expresamente en las diferentes propuestas curriculares, consideramos imprescindible que se contemple un espacio horario específicos para llevar a cabo un trabajo sistemático, continuado y consciente en el ámbito de la educación moral, si lo que se pretende es conseguir el desarrollo integral de los alumnos/as no sólo a nivel de conocimientos sino también, y sobre todo, en relación a la formación de la personalidad moral.

\section{Notas}

1 Desde 1908 hasta 1934 se celebraron seis Congresos Internacionales de Educación Moral. El primero se celebró en Londres del 25 al 29 de septiembre de 1908; el segundo en La Haya (22-27 de agosto de 1912); el tercero, en Ginebra del 28 de julio al 1 de agosto de 1922; el cuarto, en Roma del 16 al 20 de abril de 1926; el quinto, en París (24-27 de septiembre de 1930), y, por último, el sexto en Cracovia, del 11 al 15 de septiembre de 1934.

2 Desde 1915 en las diveras «Escoles d'Estiu» organizadas por el Consell de Pedagogia de la Mancomunidad de Catalunya, se reflexionaba acerca de los grandes problemas de la educación moral en las escuelas de la época. En 1932 se dedicó un ciclo de conferencias para debatir este tema, y en 1933 se aportaron una serie de principios que debían guiar la práctica de la educación moral y cívica en las escuelas de la República.

\section{Referencias}

AA.VV. (1990): Cuademos de Pedagogía. Tema del mes: Educación ética y cívica n. ${ }^{\circ} 186$, noviembre 1990. pp. $7-32$

Martinez, M.; Buxarrais, M* R. (1991): «La convención de 1989 y la educación moral». Revista Española de Pedagogía n. ${ }^{\circ} 190$, septiembre-diciembre 1991. pp. 519-534.

Piaget, J. y otros (1967): La nueva educación moral. Buenos Aires: Losada (1971): El criterio moral en el niño. Barcelona: Fontanella.

Puig, J. M. ; Martínez, M. (1989): Educación moral y democracia. Barcelona: Laertes.

Serna, J. (1990): «El proyecto Cives». Cuademos de Pedagogía n. ${ }^{\circ} 186$, noviembre 1990. pp. 18-23. 


\section{La Etica: Polémica en el curriculum escolar Isabel Carrillo, Silvia López y Montserrat Payá $C L \& E, 1992,15$, pp. 19-23}

Resumen: La perspectiva histórica puede aportar valiosas informaciones que orienten los análisis de cuestiones actuales. Así ocurre, por ejemplo, con el planteamiento transversal de la asignatura de Etica. A partir de una breve síntesis de debates habidos a comienzos del siglo $\mathrm{XX}$, preferentemente en Europa, se aboga por un enfoque explícito y sistemático de la educación ética y en valores.

Datos sobre los autores: Isabel Carrillo, Silvia López y Montserrat Payá, son licenciadas en Pedagogía y miembros del Grupo de Investigación en Educación Moral (G.R.E.M.) de la Universidad de Barcelona.

Dirección: Departamento de Teoría e Historia de la Educación, Facultad de Pedagogía, Universidad de Barcelona, Baldiri Reixac, s/n 08028 Barcelona. Tel (93) 3333466.

(C) De todos los artículos deberá solicitarse por escrito autorización de CL\&E y de los autores para el uso en forma facsímil, fotocopia o cualquier otro medio de reproducción impresa. CL\&E se reserva el derecho de interponer las acciones legales necesarias en aquellos casos en que se contravenga la ley de derechos de autor. 